University of Nebraska - Lincoln

DigitalCommons@University of Nebraska - Lincoln

To Improve the Academy

Professional and Organizational Development

Network in Higher Education

1997

\title{
A New Starting Point for Faculty Development in Higher Education: Creating a Collaborative Learning Environment
}

Katherine Sanders

Christopher Carlson-Dakes

Karen Dettinger

Catherine Hajnal

Mary Laedtke

See next page for additional authors

Follow this and additional works at: https://digitalcommons.unl.edu/podimproveacad

Part of the Higher Education Administration Commons

Sanders, Katherine; Carlson-Dakes, Christopher; Dettinger, Karen; Hajnal, Catherine; Laedtke, Mary; and Squire, Lynn, "A New Starting Point for Faculty Development in Higher Education: Creating a Collaborative Learning Environment" (1997). To Improve the Academy. 386.

https://digitalcommons.unl.edu/podimproveacad/386

This Article is brought to you for free and open access by the Professional and Organizational Development Network in Higher Education at DigitalCommons@University of Nebraska - Lincoln. It has been accepted for inclusion in To Improve the Academy by an authorized administrator of DigitalCommons@University of Nebraska - Lincoln. 


\section{Authors}

Katherine Sanders, Christopher Carlson-Dakes, Karen Dettinger, Catherine Hajnal, Mary Laedtke, and Lynn Squire 
Sanders, K., Carlson-Dakes, C., Dettinger, K., Hajnal, C., Laedike, M., \& Squire, L. (1997). A new starting point for faculty development in higher oducation: Creating a collaborative learning enviromment. In D. DeZure (Ed), To Improve the Academy, Vol. 16 (pp. 117-150). Stillwater, OK: New Forums Press and the Professional and Organizational Development Network in Higher Bducation. Key Words: Faculty Development Programs, Change Strategies, Organizational Development, Active Learning, Team Teaching, Peer Teaching.

\section{A New Starting Point for Faculty Development in} Higher Education: Creating a Collaborative Learning Environment

\section{Katherine Sanders}

\section{Christopher Carlson-Dakes}

\section{Karen Dettinger}

\section{Catherine Hajnal}

\section{Mary Laedtke}

\section{Lynn Squire}

University of Wisconsin-Madison

Traditional faculty development approaches often focus on teaching faculty skills to use in their classrooms. In order to have a deeper cultural impact, we have found it useful to start the conversation at a different point than teaching skills; that is, to have faculty learn how 
people learn by experiencing a learning environment that is substantively different than their previous classroom experiences. Our program, Creating a Collaborative Learning Environment (CCLE), has been successful in helping faculty from diverse disciplines at a major research institution to work together to learn about learning and redesign teaching.

What do we need to do to encourage, facilitate, and support learning in our classrooms? One starting point is to help faculty imagine and experience a non-traditional classroom environment. At the University of Wisconsin (UW-Madison), we have designed a faculty development program that creates a collaborative learning environment for faculty. We help them learn about learning and reflect on their beliefs about learning and learners by guiding them through a set of activities designed to help them rediscover and articulate how people learn. We feel that this program sends a consistent message to faculty about experiential, collaborative learning by "practicing what it preaches." We don't hold it out as "the answer," but we do find that it does well what it has been designed to do.

We offer faculty volunteers information resources and a structured set of activities to help them learn about learning and to reflect deeply on their teaching while collaborating with colleagues from across disciplines. Our program has been named by the faculty participants, "Creating a Collaborative Learning Environment" (CCLE). It has served over 85 faculty volunteers from 34 departments as diverse as Mechanical Engineering, Atmospheric and Oceanic Sciences, History of Science, Urban Planning, Nursing, Math, Law, and African Languages.

In this paper, we discuss the program background, mission, theoretical foundation, structure, activities (with an emphasis on the first year of participation), and its effects on faculty views of the teacher's role. We describe these changing views as a progression of insights that faculty tell us they discover through their participation in CCLE. 


\section{Background}

The theoretical approach and applied structure of CCLE were developed in an Industrial Engineering dissertation (Sanders, 1993) that studied faculty in the College of Engineering. Faculty volunteers changed their attitudes towards teaching, increased their motivation for teaching, and changed their classroom behaviors as a result of participating in an experimental collaborative program. A comparison group of faculty who attended only teaching workshops changed neither their attitudes nor their classroom behaviors. Following the dissertation study, the small group of enthusiastic faculty participants submitted a proposal to the Dean requesting that existing grant monies earmarked for undergraduate education improvement be used to continue the program college-wide. He approved their proposal and the pilot program was created in the College of Engineering, lasting from September 1993 through August 1995.

After a successful two-year pilot program serving over 40 engineering faculty, CCLE was awarded a three-year grant from the Department of Education Fund for the Improvement of Post-Secondary Education (FIPSE) to expand its services across a number of colleges at UW-Madison. The program is currently housed in the Wisconsin Center for Education Research and serves faculty from Engineering, Letters \& Science, and Agricultural \& Life Sciences.

Faculty volunteers and their enthusiasm for program continuation have been the driving force behind CCLE's success. From its inception, CCLE was designed to be a collaborative approach to the redesign of faculty work built on a grassroots, faculty-driven effort. It was never a program that was instituted in a hierarchical manner. Instead, administrative support was provided as a response to a need expressed by faculty. In combination with CCLE's structured activities and built-in evaluation processes, these unique origins have proven to be important factors in the program's success.

In this paper, we describe the structure of the program, with emphasis on the activities in Stage 1: Facilitated Learning Teams, in which faculty spend considerable time learning about learning and experiencing a special type of collegial collaboration. We feel that this beginning is the crucial step for getting faculty on the "same page" in 
continuing discussions. Finally, we summarize one of the major themes faculty describe to us as they move through the program: the changing view of the teacher's role.

\section{Program Mission}

Creating a Collaborative Learning Environment (CCLE) is a process that centers on the construction of knowledge in faculty teams. CCLE provides a support structure for group work, exposure to general educational information, and preparation for practitioner action in the classroom. Volunteers are asked to make a commitment to attend team meetings; to share their experiences in teaching and learning; to cooperate with other faculty; to consider new ideas, perspectives, and techniques; and eventually to be a resource for other faculty participants.

CCLE provides an ongoing learning experience for intense reflection, group knowledge construction, and, in the advanced stages, guided practice and continued exploration for participants. Thus, there is a higher probability that faculty will sustain and continue innovation in teaching and course development.

CCLE is not a quick fix to higher education reform, nor is it a "teaching technique" program. As one of the faculty advisors frequently says, "CCLE does not give you a list of ten pet tricks for teaching." What CCLE provides is a set of structured activities and a regular time period for faculty dialogue and reflection on learning and teaching. CCLE also helps faculty create their own systematic framework for examining learning and teaching so that relationships and interdependencies can be examined at a deep level.

While CCLE does not posit that there is "one right answer" to improve learning and teaching, there are a number of underlying assumptions in the program's philosophy. We assume that faculty participants have considerable exposure to and experience with the traditional teaching and evaluation methods of lecture, homework assignments, and midterm and final examinations. CCLE is structured to introduce faculty participants to alternative approaches to teaching by creating a nontraditional experience for them as learners. We hope to stimulate thought about the appropriateness and value of collabo- 
rative and cooperative approaches to teaching and learning; and for those faculty already experienced in these methods, we hope to provide an opportunity for further reflection, extension, and application to new settings.

\section{Theoretical Foundation}

Our approach to faculty development is based on theory from diverse disciplines. The foundation is built upon theory and research in: (1) the characteristics of learning organizations (Argyris, 1989; Brown \& Sommerlad, 1992), (2) job design and enrichment theories (Herzberg, 1970; Hackman, Oldham, Janson \& Purdy, 1975), (3) organizational design and employee ownership structures (Lawler, 1986), (4) action research models of professional development (Zuber-Skerritt, 1991; Schratz, 1993), (5) action research practices in teacher education (Zeichner, 1993; Altrichter \& Posch, 1989), (6) action research applications in educational reform (Kemmis, 1991), (7) and peer review structures in higher education (Hutchings, 1996; Quinlan, 1996).

Action research is a phrase used to describe research done by practitioners to improve their own work. In this case, the action researcher we refer to is the classroom teacher. Based on Lewin's work (1947a, 1947b), action research consists of a spiral of experimentation activities: analysis, conceptualization, planning, implementing change, re-analysis, re-conceptualization and re-planning, etc. The intent is to generate social knowledge by causing change and then studying its effects on social dynamics (Marrow, 1969).

A common theme across these disciplines is the salience of designing professional development experiences that are meaningful and stimulating to the employee. Thus, jobs are redesigned or experiments are performed by the employees themselves, the people doing the work, in order to make the work more effective and satisfying. In the context of higher education, the "work" we refer to is teaching, and the people performing the work are the faculty themselves. When designing a development program from this type of theoretical foundation, faculty are assisted in their efforts to develop themselves as 
teachers while they are involved in changing and reflecting on their own teaching.

The goal of CCLE is higher education reform from the inside; that is, by faculty practitioners. This goal is shared by some education reform efforts in K-12. For example, Ken Zeichner has created a professional development action research program for $\mathrm{K}-12$ teachers and preservice teacher education students (Zeichner, 1996; Zeichner \& Liston, 1996). In such approaches, practitioners (teachers) are given the charge of redesigning pedagogy and curriculum to improve student learning. They are provided with opportunities to gather and interpret information and then given the power to make their own decisions and act on them. Thus, organizational change moves from the bottom (i.e., the classroom level) up through the curricular and administrative levels.

In addition to the cross-disciplinary foundations that underlie CCLE activities, we find that our approach to program development is also key to our success. CCLE staff continually solicit in-depth structured feedback from faculty participants to learn what parts of the program are most effective, which need adjustment, and what needs to be created. This input is used in program development so that CCLE continually evolves to meet participants' needs.

\section{Program Structure and Objectives}

The combination of learning activities that make up CCLE's structure are many times likened by faculty to a "class." This professional development "class" is broken up into two distinctly different experiences-Stage 1: Facilitated Learning Teams and Stage 2: Advanced Teams.

The two stages of CCLE each have different emphases (see Figures 1 \& 2). Stage 1 consists of participation in two semesters of a cross-disciplinary team experience that increases awareness of the need for change and provides possibilities for changes in teaching by studying and discussing learning in-depth. Faculty have the opportunity for reflection, learning, and reinterpreting theory and practice for their own practical use. Additionally, faculty discuss and practice 
collaborative skills, such as achieving consensus and working constructively toward a team goal.

Stage 2 provides a framework for planned and recursive classroom experimentation. In this stage, faculty may choose to be involved in a Classroom Experimentation Team where they are grouped for action in the classroom using peer mentoring, observation, and formative feedback. Or, they may elect to participate in an Advanced Learning Team to study in-depth any topic of the group's choosing. Advanced Learning Teams differ fundamentally from Classroom Experimentation Teams in that they focus on a group project, similar to Stage 1 Facilitated Teams. Classroom Experimentation Teams provide a forum for faculty to advance their own personal goals with assistance from their colleagues.

The structure of CCLE allows faculty to rotate in and out of Stage 2 teams indefinitely as their interests and schedules permit. The only requirement for entering either type of Stage 2 group is successful completion of a Stage 1 Facilitated Team. That is, you cannot become part of a Stage 2 group without completing one academic year working in a team that is engaged in deep discussion and exploration to learn about learning. We have found that the majority of faculty who do not have a "successful" Stage 1 experience do not have the collaboration skills, language usage, understanding of the learning process, or comfort with the group process required to function successfully in the less structured environments of Advanced Teams.

In this paper we concentrate in-depth on the activities of Stage 1. This is not to say that the advanced stages are unimportant; in fact, we have found them to be a very effective ways of supporting faculty as they implement and assess changes and continue to explore new concepts. However, we believe that one of the major reasons CCLE has been successful in attracting and retaining faculty participation at a major research institution without use of release time, stipends, or any other extrinsic reward is because the Facilitated Learning Team helps faculty invent a fresh view of learning and collaboration. It is not uncommon for faculty in advanced stages of the program to tell us that they "miss their original team." 


\title{
FIGURE 1: Program Structure-Stage 1
}

\author{
Facilitated Learning Teams
}
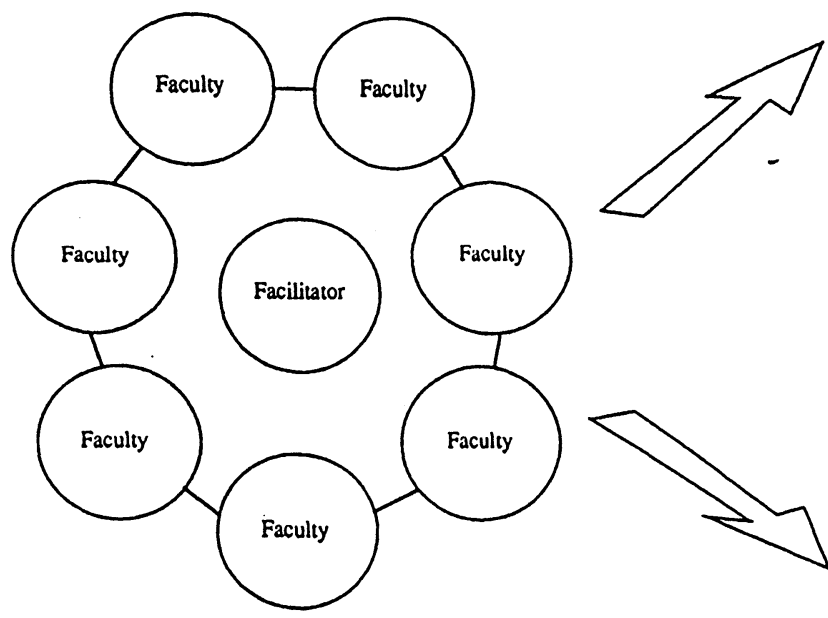

Emphasis: indepth study of learning and collaboration skills

Meeting Frequency: 1.5 hours weekly for one academic year

Activities: group project, the construction of a diagram of the learning process
Outcomes:

* ability to read education literature and discuss with colleagues using a common language

*ability to collaborate in a group and defer to group's best interests

*ability to critique and evaluate teaching based on assumptions about learning

*ability to implement classroom changes

*awareness of the need for multiple approaches to student assessment 


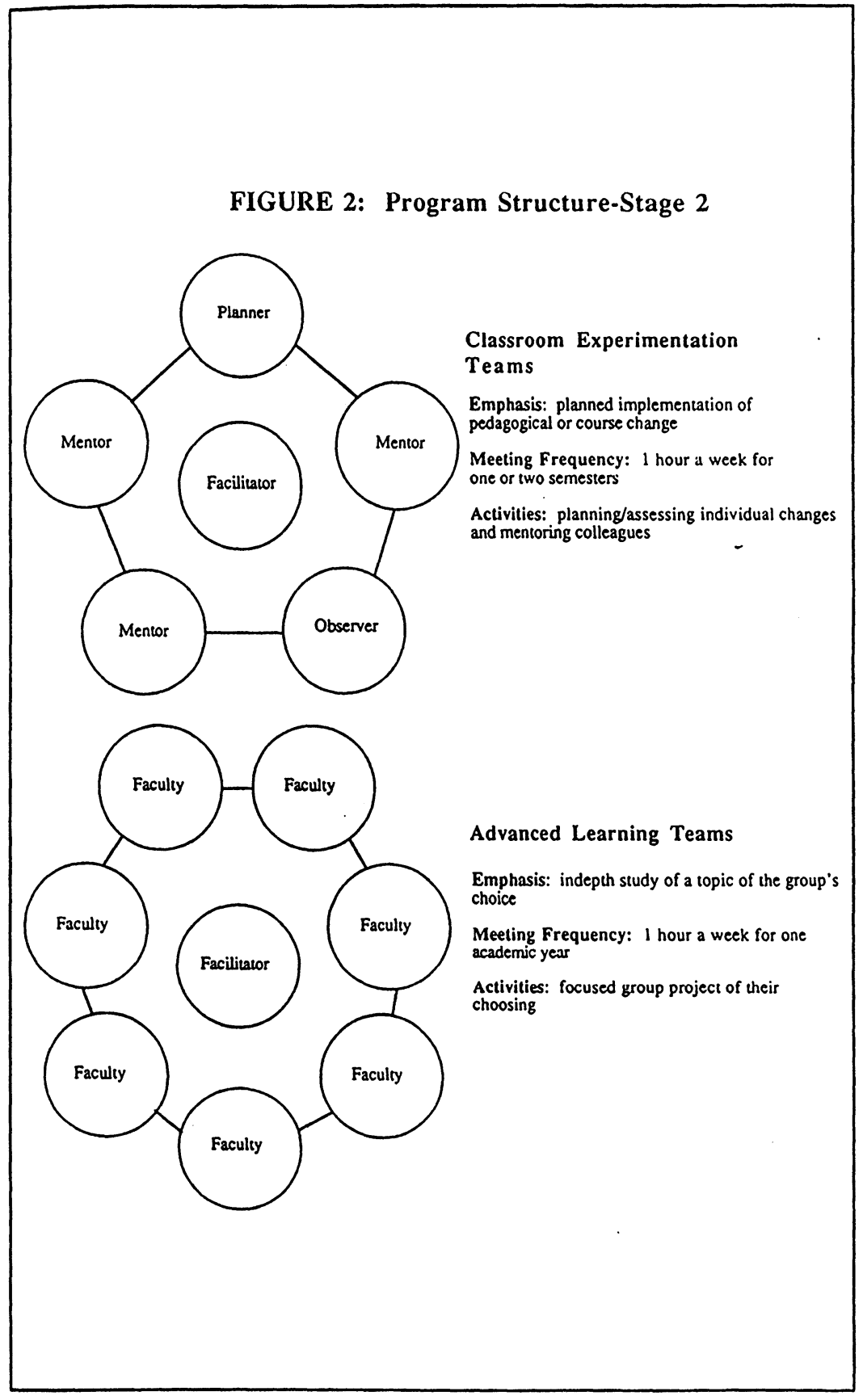




\section{Recruitment of Participants}

Now that CCLE has established a presence on campus, our approach to recruiting participants has changed. In order to garner support and interest in the first two years of the pilot program, the CCLE Director made a personal visit and brief presentation at the first department meeting in each of the nine departments in the College of Engineering. She was accompanied by a faculty participant from the first CCLE team who shared his thoughts about participation. Participation has always been purely voluntary, and there were never any external rewards provided, such as release time or stipends. In addition to the departmental meeting visit, each faculty member received a flier that contained a description of the program and registration form. The fliers were sent out several weeks before the beginning of the Fall semester, and teams were formed based on scheduling availability.

The program expansion has required a change in recruiting methods. Participation remains strictly voluntary, and we continue to rely heavily on fliers which are sent out to every faculty member in the Physical Sciences Division and the Teaching Academy (see Appendix: Recruitment Flier). However, because of the large number of departments, CCLE staff and participants are no longer able to visit each department meeting. As a result, the intimacy of the personal testimonials from the CCLE staff and faculty participants has been lost. In place of the departmental visits, we rely on the critical mass of participants who support and advocate participation in the program at their own department meetings. We ask them to talk with their friends about CCLE. Recently, because of these informal channels of communication, the Schools of Nursing, Business and Veterinary Medicine have asked us to advertise to their faculty. As we become established, we are increasingly able to rely on our reputation as a stimulating, rewarding, and fun faculty development experience.

\section{CCLE Stage 1 Participant Outcomes}

We have emphasized the importance of a successful Stage 1 experience. From our perspective, success means that at the end of an academic year in a Stage 1 CCLE Facilitated Learning Team, faculty will have had an experience that augments and enriches their previous 
understandings of learning and teaching and helps them to expand their:

- willingness and abilities to re-examine continually and articulate beliefs about the process by which people learn.

- abilities to collaborate in a group and defer to the group's best interests when reaching consensus.

- interest in exploring education literature and discussing it with colleagues based on a common language and basic understanding of the learning process.

- abilities to critique and evaluate teaching techniques based on underlying assumptions about learning to determine whether a technique is appropriate for use or modification in their own classroom and/or discipline.

- ability to select and implement changes in the classtoom (pedagogy and content) while envisioning possible/probable outcomes for a diverse student body.

- awareness of the value of multiple and diverse approaches for the assessment of student learning and evaluation of classroom practices.

The goal of CCLE is to help faculty to question critically their own teaching and that of others so they can make informed choices about how to increase the potential for learning in their classrooms and throughout the curriculum. CCLE does not explicitly advocate any one approach or content over another, but it does model a collaborative learning environment that encourages diversity and multiple ways of knowing. However, CCLE does not review or emphasize "traditional" pedagogical approaches or techniques. We assume that university-level faculty have been exposed to such approaches (e.g., lecture) and that many of them are experts in traditional methods. Faculty who express interest in learning about traditional techniques, or any techniques in-depth, are referred to other campus resources. CCLE attempts to open doors to perspectives and approaches that faculty may not have been exposed to before and to create a collegial environment of exploration and excitement. 


\section{CCLE Stage 1 Program Activities}

Stage 1 requires two semesters of weekly participation in a Facilitated Team (see Stage 1 Activities in Table 1). It begins with two, one-and-one-half-hour sessions in which participants read and discuss learning and teaching theories. Faculty also discuss teamwork skills that apply to their own CCLE team and perhaps also to student teams in their classrooms. Following the discussions, faculty participants begin attending weekly one-and-one-half-hour team meetings. The teams of seven to eight faculty members are facilitated by a CCLE staff member. CCLE provides the facilitator, a collaborative task that requires the involvement of all team members, and a structured process that allows teamwork skills and learning to evolve. It is important that the task chosen for teamwork illustrates connections between organizational and individual contributions to teaching improvement.

In the first three weeks of team meetings, each team creates its own ground rules for meetings and defines a group problem statement describing a specific reason for improving undergraduate education. This problem statement serves as a rationale for the group's collaborative work. One team problem statement was:

Our educational system does not encourage or enable students to (a) synthesize knowledge, (b) solve problems creatively, and (c) think critically. Consequently, many of our students do not acquire ownership of knowledge, expand their views of the world, or alter the way in which they think about it. ("A Team," 1994)

In contrast, another team's problem statement was,

UW students deserve an experience that motivates them to learn, love learning, and engage and challenge their world. ("Tota Team," 1996)

You might notice that the second problem statement was not stated as a negative statement. The Iota team was our first group comprised completely of Letters \& Science faculty (no engineering faculty). This group was very diverse, with members from the sciences, math, history, languages, and law. The greater number of faculty from the social sciences and humanities affected their interpretations of a "problem statement." Although it is a common phrase in engineering, 


\begin{tabular}{|c|c|c|}
\hline \multicolumn{3}{|c|}{$\begin{array}{c}\text { TABLE } 1 \\
\text { CCLE Stage 1: Facilitated Team Activity Overview }\end{array}$} \\
\hline Topic & Description & Purpose \\
\hline $\begin{array}{l}\text { Introductions/Start- } \\
\text { up }\end{array}$ & $\begin{array}{l}\text { Team introductions } \\
\text { Groundrule setting }\end{array}$ & $\begin{array}{l}\text { Meet colleagues and reach } \\
\text { agreement on how the group will } \\
\text { function }\end{array}$ \\
\hline $\begin{array}{l}\text { Acthilty A: } \\
\text { Teammork and } \\
\text { Education Overview }\end{array}$ & $\begin{array}{l}\text { Read and discuss assigned } \\
\text { materials }\end{array}$ & $\begin{array}{l}\text { Exposure to general information on } \\
\text { collaboration, loaning styles, } \\
\text { teaching approaches }\end{array}$ \\
\hline $\begin{array}{l}\text { Activity B: } \\
\text { Team Problem } \\
\text { Statement }\end{array}$ & $\begin{array}{l}\text { Generate consensus } \\
\text { statement on problem in } \\
\text { higher education }\end{array}$ & $\begin{array}{l}\text { First collaborative task, establishes } \\
\text { some common language and } \\
\text { themes, provides group focus for } \\
\text { future discussions and activities }\end{array}$ \\
\hline $\begin{array}{l}\text { Activity C: } \\
\text { Problem Context } \\
\text { Diagram }\end{array}$ & $\begin{array}{l}\text { In pairs, create team } \\
\text { cause/efiect diagram using } \\
\text { problem statement }\end{array}$ & $\begin{array}{l}\text { Larger collaborative task, gives } \\
\text { overview of factors contributing to } \\
\text { problems in higher education, shows } \\
\text { possibilities for impacting problem }\end{array}$ \\
\hline \multicolumn{3}{|c|}{$\begin{array}{l}\text { NOTE: Almost always, a deep understanding of how people leam and the attributes } \\
\text { that affect learning can impact the problem statememt. CCLE concentrates on } \\
\text { learning so that faculty can create teaching approaches and curricula to address a } \\
\text { multitude of cumrent and future challenges. }\end{array}$} \\
\hline $\begin{array}{l}\text { Activity D: } \\
\text { Individual Leaming } \\
\text { Diagrams }\end{array}$ & $\begin{array}{l}\text { Individuall create a drawing } \\
\text { of how poiole loam and what } \\
\text { might help/hinder loaming }\end{array}$ & $\begin{array}{l}\text { Requires personal reflection and } \\
\text { deeper thought about how people } \\
\text { make meaning; requires use of } \\
\text { personal experiences and some } \\
\text { synthesis of background information; } \\
\text { creates basis for team diagram }\end{array}$ \\
\hline $\begin{array}{l}\text { Activity E: } \\
\text { Collaborative } \\
\text { Leaming Diagram }\end{array}$ & $\begin{array}{l}\text { Using individual drawings, } \\
\text { create a consensus } \\
\text { depiction to show how } \\
\text { people leam and what might } \\
\text { helphinder leaming }\end{array}$ & $\begin{array}{l}\text { Major activity of the program, } \\
\text { requires team to create visually and } \\
\text { verbally, develop and explore new } \\
\text { ideas, articulate their deepening } \\
\text { understandings of leaming; requires } \\
\text { development of language and new } \\
\text { concepts }\end{array}$ \\
\hline $\begin{array}{l}\text { Activity F: } \\
\text { Fall Semester } \\
\text { Meeting }\end{array}$ & $\begin{array}{l}\text { Show and discuss team's } \\
\text { work to date with CCLE } \\
\text { participants (Stages } 1 \text { and 2) }\end{array}$ & $\begin{array}{l}\text { Provides forum to see the work and } \\
\text { meet other faculty teams, opportunity } \\
\text { to give feedback to faculty advisors } \\
\text { and staff }\end{array}$ \\
\hline
\end{tabular}




\section{TABLE 1, Continued}

\begin{tabular}{|l|l|l|}
\hline $\begin{array}{l}\text { Activity G: } \\
\text { Collaborative } \\
\text { Course Module } \\
\text { Design }\end{array}$ & $\begin{array}{l}\text { Using the leaming diagram, } \\
\text { collaboratively design a } \\
\text { course module of their choice }\end{array}$ & $\begin{array}{l}\text { Helps synthesize new } \\
\text { understandings of loaming, allows } \\
\text { group to apply lonowlodge in overall } \\
\text { course plenning and class session } \\
\text { activities }\end{array}$ \\
\hline $\begin{array}{l}\text { Activity H: } \\
\text { Spring Semester } \\
\text { Meeting }\end{array}$ & $\begin{array}{l}\text { Discuss team's work with } \\
\text { other CCLE groups }\end{array}$ & $\begin{array}{l}\text { Shares toam's work with others, } \\
\text { provides closure, opportunity for } \\
\text { feodback, and planning for the future }\end{array}$ \\
\hline
\end{tabular}

their feedback to us was that from their perspective it was not a comfortable way to look at the world. This team wished to state their "problem" as a positive statement of intent, thus their phrase took a somewhat different form. Regardless, if a team can come to consensus on a statement that serves as a rallying point or common goal, we find it sufficient for our purposes. The discussion of and resulting statement of the goal are important. They create a common purpose for the team to move toward; and the facilitator can then refocus the team's discussions around this common point in the future.

From that point, we have found it useful to have faculty construct an overview of the system influencing the processes of teaching and learning. This exercise helps to focus later discussions about the effects of pedagogy and curriculum. We feel that faculty must understand the organizational contexts of the department, college, and university before redefining their specific roles and practices within those contexts.

During much of the remainder of Stage 1, the team constructs a diagram to represent the process of learning. The team members draw upon their own experiences as learners as well as the information they discussed during the introductory education workshops. In other words, faculty collaborate in a group learning experience to integrate their own experiences as learners with education theory and represent this as a consensus group project. Faculty are not only creating and internalizing learning content by making their own connections and interpretations, but they are also learning through experience how to work collaboratively in a team. 
Stage 1 concludes by explicitly tying the learning process to the teaching process. Faculty identify the elements of their team's learning process diagram that are most essential for learning to take place. These are the key points they will keep in mind as they transition to the role of the teacher. The team "graduates" Stage 1 by using what they have learned to design a section of a hypothetical course. The course section can be anything of the group's choosing that all team members have interest in and can contribute to. (The more diverse the team members' disciplines, the more creative they must be in choosing a course topic.)

In addition to participating in a facilitated team, faculty members are also observed in the classroom by CCLE staff and provided with periodic formative feedback. This feedback is used only as a basis for discourse about teaching goals, not for evaluative purposes, and is completely confidential. The conversation during the feedback session allows faculty to hear perspectives on their classroom activities that are different from that of their peers or students. It also allows the CCLE staff to get to know each of the faculty participants on a one-to-one basis.

Why do we begin with the topic of learning instead of beginning with conversations of teaching? We have found that when we focus attention on learning, we help commonalities across disciplines to emerge. Additionally, unless participants are able to make effective connections between learning experiences, conversations about various teaching methods will be scattershot. We feel that in order for faculty to have deep conversations about teaching, they must first be able to explain for themselves why some teaching methods may work better than others given certain constraints and why all methods are not equally effective for all students. This understanding lays the foundation for faculty to develop their own approaches to teaching, appropriate assessment techniques, and evaluation methods.

To design a truly collaborative learning experience, the central task must be difficult enough to require the creativity of an entire group, yet rely on a combination of personal reflection and experience that can be contrasted and combined with theory and literature. Everyone must be able to contribute, and there must be more than one possible answer. In fact, when working with faculty, we emphasize an 
exercise that requires individuality and multiple interpretations. Given that university faculty are typically professionals who have been educated to act as very independent "experts," we find that they resist standardization, are analytically rigorous, and can be very creative. We try to design activities that capitalize on those strengths.

Faculty tell us that drawing the learning process as a group has proven to be the most challenging, motivating, and engaging learning experience in CCLE. Faculty typically enter CCLE with a great deal of experience in addressing the classroom from the teacher's point of view, but most have never explicitly examined the learning process. Even though they are all experienced learners, their CCLE experience is the first time they must focus on learning from the learner's perspective. Many of them tell us that their CCLE experience helps them identify with their students' perspectives in a new way. It helps them remember what it is like to be a student, which frees them to see their role as teacher in a new light.

Although the focus of CCLE is on providing a structure for personal reflection and group collaborative learning, we supplement this teamwork experience by introducing outside resources. Journal articles and study results, guest speakers, and workshops stimulate participants and introduce them to specific teaching issues. Outside readings on topics such as student retention in science and engineering education (Seymour \& Hewitt, 1994), gender issues in learning and teaching (Clinchy, 1988), and assessment and evaluation techniques (Angelo \& Cross, 1993; Cross, 1987) are given to faculty participants at appropriate times during their Facilitated Learning Team and Advanced Team participation. While the program is not centered on outside readings, CCLE staff use them to supplement the team learning experience. Our aim is to interject new ideas as teams become more open to divergent views and perspectives and more curious about education reform outside their disciplines. In the more diverse teams, team members themselves raise some of the issues we previously used research articles to provoke. For example, gender issues in learning and teaching are now emerging naturally when women faculty are present. In the first two years of the pilot program in engineering, often the only woman present was the facilitator. Now we can use the 
literature to augment and reinforce real life experiences instead of using it to introduce them.

Models of teaching and learning are introduced, but they are not the keys to success in this program. We do choose models we feel are most connected to practice, but these are not the vehicles for the initial "ah hah!" or the introspection. Faculty must prove to themselves that there are patterns and interdependencies within learning and, ultimately, teaching. When they do so, they tell us they are truly convinced:

[CCLE] really changes almost everything. It certainly changes, as I've said, the way I see what I do. It changes the way I see what I want to do in terms of teaching. It changes the way I see what classes I think our department ought to be teaching, what classes I think we ought to be developing, what classes I think we ought to be getting rid of. So, in that sense, I think involvement in the program itself, and raising my own consciousness in teaching and learning, I think in a sense-almost everything is different now.

In our experience, if faculty attempt to rush directly into changing specific teaching techniques without an initial examination of their underlying assumptions about learners and learning, they are likely to make minor changes. They tend to ignore the larger issues of curriculum reform or the meaning of alternative pedagogies. Perhaps it's because it is easy to reject what we do not fully understand or what we feel does not pertain to us. However, when faculty have wellformed connections and associations to build on they can more easily enrich, deepen and ultimately transform their understandings and classtoom practices.

\section{Effects on Faculty Attitudes and Practices}

We evaluate the effectiveness of CCLE by studying faculty responses and looking for patterns and common themes within and across teams. Our intent is to understand the participants' experiences so that the program can be responsive and reflexive to faculty members' needs as learners. Faculty are interviewed at the beginning of their participation in CCLE and again at the end of each semester. Interviews are fully transcribed, interpreted, and analyzed by CCLE 
staff. In these interviews, faculty describe their learning and give input for program improvement. Teams also have a semi-structured feedback discussion at the end of each semester in which they make recommendations to CCLE staff. To document and evaluate behavioral change, faculty are observed in the classroom, and descriptive information on teaching approach and content is compared across semesters of participation.

By documenting and tracking faculty learning, feedback, and activities, CCLE staff continuously evaluate the program's progress and success in serving faculty needs for professional development. This formative program evaluation has led to a number of innovations and refinements. Ongoing formative evaluation also allows CCLE staff to respond to faculty needs for personal attention and feedback from CCLE facilitators (who many times are viewed as "teachers").

Our interpretative phenomenological analysis of interviews with CCLE faculty since 1993 shows participation in the program to be an intense learning experience with lasting effects on faculty attitudes, motivation, and practice. Phenomenological research and its subsequent findings lead to the development and presentation of themes which emerge from the data, rather than "results" which are commonly reported in other forms of research.

The themes that emerge from our work are fluid. Just as faculty are continuously developing new understandings regarding teaching and learning, our understandings of how faculty learn and change in CCLE continue to grow and deepen. As our understanding of the faculty experience develops, so do the themes we use to tell their stories. Therefore, we consider our themes as work-in-progress, constantly unfolding. Throughout our conversations with faculty, we have heard descriptions of a number of transformations in their views which have led to several themes: the evolution of collaboration, of self-reflection, of peer mentoring, and the evolution and expansion of the teacher's role. Although these themes are listed as distinct entities, they are in actuality very highly related and interdependent. Only one of these themes will be discussed in this paper: the evolution and expansion of the teacher's role. 


\section{Theme: Evolution and Expansion of the Teacher's Role}

The theme, Evolution and Expansion of the Teacher's Role, implies a progression or development in perspective. We have chosen to present this progressive theme as we might typically hear it discussed by faculty, in their voices (i.e., in the first person). The following discussion is related as a progression of questions/concerns that reflect a transformation from teacher-centered to student-centered pedagogy. We begin with a typical statement from a "novice" in CCLE.

\section{A. Learning is complex and has many variations. What should I do to address the diverse learners and learning styles in my classroom?}

The first time that faculty are asked about their learning in CCLE, they are likely to remark that learning is "complex" and much more involved than they had ever imagined. Often at this stage in their experience, they feel paralyzed by their exposure to the variety of learning styles and their first attempts at clarifying the complex process of learning itself. A typical remark during the first semester of Stage 1:

I guess what I've learned about teaching is that I have to think about learning more because I know that not everyone is going to learn the same way that I learn. (Stage 1 Participant)

At this point, participants have not begun to make changes in their classrooms. Even for an award-winning teacher, the wealth and depth of new knowledge can be overwhelming. The majority of participants move beyond this initial confusion within a month or two of working in the program. Most are very eager to find "the" answer to improving their teaching.

B. Learning is a process of making connections and testing them, but I'm still confused about how to help stu- 


\section{dents do this in my classroom. How and what are the stu- dents learning?}

This is the point in CCLE when faculty begin to experiment in the classroom. They are usually tentative and seldom can verbalize exactly why they chose one technique over another. Goals for the student experience are fuzzy. Faculty usually oscillate back and forth between their own perspectives as teachers and the students' experience as learners. However, this is also the point when faculty begin to verbalize what they believe the process of learning to be. They speak of "connections," "associations," "naturally inductive," "a circular, recursive process," and "unique to every individual."

Gathering information from the students, information that is usually collected informally and is relatively unfocused in nature, is one of the most common themes in this stage. One might characterize this stage in experimentation as "fishing." If something works well, faculty are excited and try it again. If something does not work as expected, they cannot yet explain potential reasons to themselves and, therefore, usually are convinced that a technique "won't work for my discipline/specialty/course/room/students." There is not yet an underlying "theory" to explain how, when, or why learning takes place sometimes and not other times. Much remains mysterious, but faculty are stimulated by the new information and the potential for a positive student response.

Faculty typically slow their pace; interact with students; and have students do board work, give talks, write summaries, and demonstrate homework problems. The assumption is that, if the teacher knows where confusion arises, she/he can clarify or intervene. Also, by interacting with the students, many faculty attempt to develop a more informal and less intimidating learning environment in which students feel comfortable asking questions and contributing to discussions.

\section{I know how to help students make associations and con- nections in my classroom. How are my new approaches working?}

Typically, the next story faculty tell us is about an increase in their confidence about what learning is and how it takes place. These faculty 
are becoming comfortable with their own understanding of learning and have many ideas for helping students learn. Learning now takes on some stronger associations with teaching techniques, and this is where a variety of techniques are developed and implemented, with the emphasis on having students "active" or "engaged" with the material. Many faculty try to design student activities that help students make connections between theory and practice, or they try to illustrate explicitly some positive connections and associations for students.

Faculty continue to gather information about how and what the students are learning, but this time with respect to more specific goals for student learning. They are more tenacious when things don't work as planned. They collect feedback, refine their ideas, and try again. They have an underlying explanation for themselves, a framework of how learning happens that they draw on when things don't work as planned. Evaluation tools are either informal or formal, and may be periodic or end of semester. This is when the excitement begins for faculty. They experience some success in the classroom and start to view the classroom from the learner's perspective on a consistent basis. They are able to express their emphasis on and commitment to active learning.

...I think the group activities are really worthwhile. People should be able to interact with their peers. And, you know, learning, helping your peers, teaching them, and learning from your peers, that is one of the best ways to learn. I really think that is helpful whenever I can build that in. (Stage 1 Participant)

What I need to work more on is getting them to kind of talk about their accountability and how they came up with the solution as a group... I wanted more discussion about how you arose at this [answer] as a group, if you did or did not. And as I made my expectations more clear, they did improve. (Stage 2 Participant)

At this point it is typical for faculty to use techniques that provide a context for the course content, such as demonstrations, videos, simulations, examples, and industrial applications. They consider student backgrounds by asking students for information about their skills and experiences. Some try to tailor activities and examples to 
particular student interests with the intent of engaging students and helping them connect the new knowledge to previous learning.

\section{The collaborative process of asking our own questions and constructing our own answers is working for us in CCLE. How can I help students to ask their own ques- tions and build their own connections from their own ex- periences?}

This question is asked by faculty certain of the long-lasting effects and high value of having learners create connections from their own understandings and experience. (This is a mirtor of the collaborative knowledge construction in CCLE.) However, as this possibility is explored, there is conflict. The trade-off between pace and content versus students developing, exploring, or creating seems almost overwhelming. Faculty start experimenting to find a balance between what they know is a powerful learning experience and the requirements of "covering" material.

This is a difficult point in growth as a teacher, and many of the questions of balance reoccur when transferring learning to another course or another set of topics. Evaluations of the classroom usually become more formal and sophisticated at this point, with faculty working hard to develop and focus their own specific tools for feedback about course content and structure. Student feedback is directly incorporated into the course.

Not all faculty have made this connection between CCLE and their own classrooms, but for those who do, it's a powerful personal discovery. In the words of two CCLE participants who see their experiences as "students" in CCLE as a model for possibilities in their own classrooms:

And I'd say the process that you can expect is - the process that you as an instructor go through is the process that we expect our students to go through. So it [CCLE] mirrors what we do in the classroom to some extent. And maybe to put it another way, if it's successful for us then maybe the classroom ought to mirror what we go through....I suppose that one thing you can expect to get out of this is to learn how you learn and to ask the question, "Why am I teaching differently than the way I learn?" (Stage 1 Participant) 
So, in one sense, you become the person that we're interested in trying to help. But in another sense, you also are part of this group that is trying to help yourself understand some aspect of the process better than you do now. If you believe what our group believed about learning, that [deep] understanding is more likely to come if you're involved in the development of your own understanding, rather than if it is presented to you as a completed work where you say, 'Read it. That's it." (Stage 1 Participant)

At this point it is common to see faculty asking students to teach each other. They use group techniques with and without roles, for constructing exams, and think/pair/share to work on problems and provide feedback to each other. The group activities take place in the classroom, in labs, and outside the classroom with homework assignments, group projects, and case studies. Faculty also use classtime for students to practice skills and give input into assignments so that the instructor and fellow students can give feedback and encouragement. They spend more time getting students to design classroom activities. As one professor describes:

This time, I used much more [student] input in designing the debate, designing the issues that we want to talk about. So instead of making just a handout assignment, I had the class help define the assignment. Ilaid the groundwork or the framework and then the details on the issues and the grading and the structure of it as a group process. (Stage 1 Participant)

When these faculty have some success and feel somewhat comfortable with getting student input into the design of classroom activities, some of them make one last conceptual transition. They change their underlying philosophy of who "owns" the classtoom. That is, they move past getting students to participate in the design of activities nested within a structure they created to the more complex issue of how to create student-directed learning environments. In the following section, we hear faculty discuss the implications of de-centering themselves as "the teacher" and authority figure. 


\section{E. I am a resource provider and colearner in our class-} room. How can I create a place for students to direct their own learning experience?

At this point, faculty are quite sophisticated in their questioning of teaching approaches. They have a very specific goal and underlying philosophy in mind, based on the assumption that students as learners should direct the learning experience. The teacher's role becomes whatever is necessary to provide resources or support for students to learn. Students control the majority of decision making and take on added responsibilities for which they are explicitly prepared. The distinction between "teacher" and "student" is blurred, with everyone in the classroom responsible for contributing to a successful learning experience.

Additionally, faculty are more comfortable with the choice, implementation and interpretation of classroom evaluation information. They are certain that periodic evaluation is important. They are more likely to use a combination of formal and informal, targeted techniques. Finally, they begin to reassess their traditional methods for assessing student learning. They are very curious about other avenues of assessment that are more consistent philosophically and practically with student ownership.

This final transition might be described as a shift in the vision of the classroom. Faculty shift ownership from $m y$ classroom and wondering how to get students to behave in specific ways, to talking about our classroom and their role as resource providers. The students and faculty are both teachers and learners in the classroom.

The question has become, "What can I do for students to help them learn in our classroom?" The answers are sophisticated in that they give students control of the agenda and process at differing levels dependent on context (e.g., level of course, confidence and background of students) but global in that they are implemented with the express desire to provide structure and resources to assist students to empower themselves. The following comment describes this blur between the roles of teachers and learners in the classroom:

[My role is] to provide an environment where [students] are comfortable to explore and let the concepts emerge, [a place that] motivates 
them to do that, with restraint of your ego, not that you have to show them the way, [but instead] let them find the way and question along with them. (Stage 2 Participant)

In these classrooms, the focus is on students as partners in the classroom. Though the teaching approaches might look similar in nature to those mentioned in the previous conceptualizations of teaching and learning, they differ in level and content of student activity. Students have ownership of their own learning, and the teacher sees himself or herself as a resource provider and colearner. Teaching is not something that is done to the students, but rather something that is shared. Techniques in the classroom include collaborative learning groups, asking students to choose course content, having students write their own exams, and having them teach each other and grade themselves and each other.

In general, change is common across all CCLE faculty classrooms, regardless of faculty descriptions of teaching and learning. The most common and immediate change is the increased solicitation of student input and feedback. A number of faculty take advantage of the CCLE staff's experience in questionnaire administration and interpretation, while others write and interpret their own surveys based on examples from colleagues. Regardless of how the information is collected, faculty are very motivated to seek student feedback on teaching approach and student learning frequently throughout the semester. As faculty understanding of student learning grows throughout the program, they seek out student voices more often and feel more comfortable interpreting those voices. They begin to ask the students what is working and what is not. They no longer feel a need to be seen as the distanced education expert. They recognize that change is evolutionary for themselves and their students. And we find that faculty tend to build from their successes, just as all learners do.

\section{Effects on Curriculum}

Connections to curriculum innovation are also underway. In 1994, the first team of CCLE faculty "graduates" and the CCLE Director collaborated to create and teach "Introduction to Engineering." This course was initiated in conjunction with an ARPA grant awarded 
through the National Science Foundation to the Engineering Research Center for Plasma-Aided Engineering. Its goal is to give engineering freshmen an opportunity to discover engineering by working in small design teams on a real engineering cross-disciplinary consulting project. Additionally, students get to know engineering peers and faculty in a more intimate and exploratory environment. The intent is to attract and retain a more diverse group of engineering students and to allow students to more accurately decide whether an engineering career might be of interest for them.

The course was successfully piloted during the 1994-95 academic year with approximately ten percent of the 800 engineering freshmen and was expanded in 1995 to include 220 students. The CCLE director and nine faculty volunteers who have all "graduated" from Stage 1 of CCLE continue to re-design and teach the course. (For more information about the development and evaluation of "Introduction to Engineering," see Corradini et al., 1995; Courter \& Millar, 1995.)

\section{When CCLE Works and When It Doesn't}

The majority of CCLE participants change their attitudes toward learning and teaching, and their teaching practices. As we mentioned in the previous section, some have begun to change the curriculum. After studying learning, many faculty make a relatively quick determination that effective teaching enables and/or empowers students to question and learn. Their descriptions of "good teaching" move from a laundry list of mechanistic teaching behaviors or characteristics (e.g., fairness, enthusiasm, content mastery) toward an emphasis on designing an environment and activities for engaging students' questions, imagination and reasoning. They begin seeing the teacher's role as more complex, varied, and interesting. Teaching becomes intellectually challenging and exciting again. In one participant's words:

The large part of it [teaching] would be emphasis that teaching has to focus on learning. You're a resource provider if you know what the learners need. You define parameters in the sense that you say, "Here's the topic we're going to be learning about," but beyond that you're largely a resource provider, whether that's information, direction, suggestions, organization, or whatever. It's someone who sets up the framework for learning, but you don't make learning happen. You can 
obviously inhibit it. So I have a somewhat different view on what the role of the teacher is. It's not simply to present information, but maybe a much broader role than that. Not nearly so narrow. (Stage 1 Participant)

However, not all faculty find that CCLE meets their needs. Faculty most likely to receive the greatest benefit from CCLE are those volunteers who are willing to reflect on their own belief systems and to see themselves and others from different perspectives. Those participants who feel that they enter CCLE with "the answer" and are waiting for others to catch up, or work from a perspective that there is one truth (one answer that must be converged upon), find that participation is frustrating and does not lead to their desired outcome. They find the program frustrating.

Even so, faculty show a broad range of reactions to this frustration. Some participants stay in the program, even if frustrated, because they do value the interaction with colleagues. These people may come to realize that the nature of teamwork itself is sometimes frustrating, while others may become so frustrated that they end participation. When asked what new participants might expect during their first year in CCLE, this engineering professor said:

What I would tell them to expect is a lot of frustration because you will be intimately working with people with ideas and convictions as strong as yours. You will have the charge of coming up with something, the [group] of you, with equally strong convictions and inputs coming. Expect that you cannot go in there if you go in with a set agenda or a set preconceived notion of what you will get out of it. [If you do,] you will not necessarily get that, and you will be frustrated as a result. So, it's kind of like you must go in with an open mind and let it take you where it goes. Enjoy and learn from the ride, and take it as that without expecting something certain. (Stage 1 Participant)

Individuals are able to adjust their expectations to varying degrees. An inability or unwillingness to compromise original expectations of either progress (in reaching their own individual goal) or process (expectation of what the program should be like) is a sure-fire sign that a great deal of frustration is on the way. Everyone becomes frustrated at times (facilitators included), even within the most "suc- 
cessful" teams. That is to be expected in a truly collaborative peer endeavor.

What differs is the level or amount of that frustration, and more importantly, the individual's attribution of it. That is, if the person looks inwardly to see why the experience is frustrating, he or she might make a large leap in understanding, such as making a connection between the way students learn in the classroom, or identifying aspects of his/her own personality that make compromise difficult. However, if the person attributes the frustration outwardly, to the others in the team, he or she may behave destructively in a team meeting and becomes a high risk for dropping the program. Individual differences in learning styles and world views are potential causes for misfit in CCLE.

Faculty participants have continually emphasized that CCLE must provide a safe environment for open discussions. Most have expressed the concern that facilitators from positions of authority (e.g., peer faculty members, administrators) would change the dynamic in a negative way. In discussing such personal and sensitive issues as curriculum reform, gender issues, the needs of underrepresented student groups, and evaluation and assessment concerns, faculty members would be hesitant to express their views. The major responsibilities of the facilitator are to create a safe environment for discourse and then continually to refocus faculty attention on the issues at hand.

We find the translation of organizational research and theory from business settings to an academic setting in a large research university challenging but worthwhile. We've been able to contribute to the education and advancement of our faculty who are, in a vast majority of cases, already highly motivated, life-long learners dedicated to and skilled in facilitating learning with their students. They tell us that we help them develop a culture of self-reflection and collaboration in their work as teachers. We see our role as a source of stimulation and support for cultural revolution in the classroom and across the organization. We provide an opportunity for faculty to work with each other to create new options and open new doors so that they can redesign their jobs and their institutions. 


\section{References}

Altrichter, H., \& Posch, P. (1989). Does the 'Grounded Theory' approach offer a guiding paradigm for teacher research? Cambridge Journal of Education, 19, 21-31.

Angelo, T. A. \& Cross, K. P. (1993). Classroom assessment techniques: A handbook for college teachers. San Francisco: Jossey-Bass.

Argyris, C. (1989). Strategy implementation: An experience in learning. Organizational Dynamics, 18, 5-15.

Brown, H., \& Sommerlad, E. (1992). Staff development in higher echcation: Towards the learning organisation? Higher Education Qwarterly, 46, 174-190.

Clinchy, B. M. (1988). Issues of gender in teaching. Journal on Excellence in College Teaching, 1, 52-67.

Corradini, M. L., Farrell, P. V., Mitchell, J. W., Marleau, R. S., Moskwa, J. J., Sanders, K. J., \& Webster, J. O. (1995, June). A team-based design course for engineering freshmen. Proceedings of the American Society of Engineering Education Annual Conference. Anaheim, CA.

Courter, S. S., \& Millar, S. B. (1995). Final evaluation report of Introduction to Engineering, a pilot first-year design course. Madison: University of Wisconsin-Madison, Learning through Evaluation, Adaptation and Dissemination (LEAD) Center.

Cross, K. P. (1987). Feedback in the classroom: Making assessment matter. Washington, DC: American Association for Higher Education Assessment Forum.

Hackman, J. R., Oldham, G., Janson, R., \& Purdy, K. (1975). A new strategy for job enrichment. California Management Review, 17, 57-71.

Herzberg, F. (1970, September-October). One more time: How do you motivate employces? Harvard Business Review, 109-120.

Hutchings, P. (1996). Making teaching community property: A menu for peer collaboration and peer review. Washington, DC: American Association of Higher Education Teaching Initiative.

Kemmis, S. (1991). Improving education through action research. In O. Zuber-Skerritt (Ed.), Action research for change and development (pp. 57-75). Brookfield, VT: Gower.

Lawler, E. E. (1986). High-involvement management: Participative strategies for improving organizational performance. San Francisco: Jossey-Bass Publishers.

Lewin, K. (1947a). Frontiers in group dynamics: Channels of group life, social planning and action research. Human Relations, 1, 143-153.

Lewin, K. (1947b). Group decision and social change. In T. M. Newcomb \& E. L. Hartley (Eds.), Readings in social psychology. New York: Holt, Rinehart \& Winston.

Marrow, A. J. (1969). The practical theorist: The life and work of Kurt Lewin. New York: Basic Books.

Quinlan, K. M. (1990). Involving peers in the evaluation and improvement of teaching: A menu of strategies. Innovative Higher Education, 20, 299-307. 
Sanders, K. (1993). The effects of a participatory process to improve college teaching. (Doctoral dissertation, University of Wisconsin-Madison). UMI Dissertation Information Service, order number 9408582.

Schratz, M. (1993). Researching while teaching: Promoting reflective professionality in higher education. Educational Action Research, 1, 111-133.

Seymour, E., \& Hewitt, N. M. (1994). Talking about leaving: Factors contributing to high attrition rates among science, mathematics and engineering undergraduate majors. (Final report to the Alfred P. Sloan Foundation on an ethnographic inquiry at seven institutions.) Boulder: University of Colorado, Bureau of Sociological Research.

Zeichner, K. (1993). Action research: Personal renewal and social reconstruction. Educational Action Research, 1, 199-219.

Zeichner, K. (1996). Research on teacher thinking and different views of reflective practice in teaching and teacher education. In K. Zeichner, S. Melnick \& M. Gomez (Eds.), Currents of reform in preservice teacher education. New York: Teachers College Press.

Zeichner, K. \& Liston, D. (1996). Reflective teaching: An introduction. Mahwah, NJ: L. Erlbaum Assoc.

Zuber-Skerritt, O. (1991). Action research as a model of professional development. In O. Zuber-Skerritt (Ed.), Action research for change and development (pp. 112-135). Brookfield, VT: Gower. 


\author{
Contact: \\ Katherine Sanders \\ Wisconsin Center for Education Research \\ University of Wisconsin-Madison \\ 1025 West Johnson Street, Room 345 \\ Madison, WI 53706 USA \\ (608) 263-4257 \\ (608) 263-6448 FAX
}

Katherine Sanders, Director and creator of CCLE, is an Associate Scientist in the Wisconsin Center for Education Research and an Instructor in the Department of Mechanical Engineering. Her Bachelors, Masters and Doctorate are in Industrial Engineering from UW-Madison, specifically Human Factors and Sociotechnical Systems Engineering. Since her dissertation work she's been studying professional development and its links to organizational learning and institutional culture in higher education. She enjoys staying comnected to students and her engineering colleagues by team teaching Introduction to Engineering.

Christopher Carlson-Dakes is the Assistant Director of CCLE and is currently working on a Ph.D. in Industrial Engineering, Human Factors Division, from The University of Wisconsin-Madison. He has a Bachelor's Degree in Mechanical Engineering from Carnegie Mellon University and a Master's Degree in Mechanical Engineering from Pennsylvania State University.

Karen M. Dettinger, P.E. has a Bachelor's Degree in Industrial Engineering and a Masters Degree in Human Factors Engineering from UW-Madison. She was the Assistant Director of Creating a Collaborative Leaming Environment from 1994-1995. She has over ten years of experience in the private sector in facilities planning, process improvement, workforce participation and organizational design. She is currently working on a Ph.D. in Industrial Engineering focused on developing an understanding of the student culture in undergraduate engineering education.

Catherine Hajnal has recently completed her Ph.D. at the UW-Madison. Her main interests are organization and individual development, and the impacts of emerging technologies on human resource functions. She is currently involved with action research and teaching at the University of New Brunswick - Saint John Campus (Canada).

Mary E. Laedtke, OTR, has a Bachelor's Degree in Occupational Therapy from the University of Wisconsin-Madison and a Master's Degree in Health Fitness Management from American University, Washington, D.C. She was a team facilitator for Creating a Collaborative Learning Enviromment from 1995-1997. She is a Lieutenant Colonel in the United States Army and is stationed at the U.S. Army Center for Health Promotion and Preventative Medicine, Aberdeen, MD. She is currently 
working on a Ph.D. in Industrial Engineering from the University of Wisconsin-Madison.

Lynn L. Squire is currently an educational researcher with the Learning through Evaluation, Assessment and Dissemination (LEAD) Center, University of Wisconsin-Madison. Prior to working with LEAD, she was a researcher for Creating a Collaborative Learning Enviromment (CCLE). She received her Bachelors Degree in English Literature and a Masters Degree Educational Administration from the University of Wisconsin-Madison. Her interests include faculty development and the assessment of student leaming.

\section{Acknowledgments}

This work has been supported in part by grant P116B50459-96 entitled "A Process for Curriculum Reform Through Faculty Development in the Physical Sciences and Engineering" from the Fund for the Improvement of Post-Secondary Education (FIPSE) and in part by the IBM/TQM Partnership with the UW-Madison College of Engineering. Our warmest thanks to our friendly and nurturing FIPSE program officer, David Johnson, and our IBM colleague, Bill Geoghegan. We are grateful for the insight and support of our co-Principle Investigator, Associate Vice Chancellor Robert Skloot. Our thanks also to Professors Michael J. Smith, Andrew Porter, Nancy Diekelmann, Ken Zeichner, Clifton Conrad, Sandra Courter, Michael Corradini and Dean John Bollinger for their vision and input. Finally, and with great affection, we thank the CCLE faculty advisors, Patrick Farrell, John Mitchell, and David Nelson and all the CCLE participants. 


\section{Appendix \\ Recruitment Flier}

Have you ever wondered why some things you try in your classroom work and others do not?

Have you ever wondered how people learn?

For three years, faculty volunteers have been participating in a program named Creating a Collaborative Learning Environment (CCLE). Initiated in the UW-Madison College of Engineering, CCLE has now expanded to departments across the Madison campus (with emphasis on the Physical Sciences Division). It provides an opportunity for faculty to work with colleagues to learn about learning and reflect upon their teaching. The objective of the program is to help faculty develop themselves as teachers, collaborators, and learners.

If I were to describe CCLE, I would [say] it's a place where people come together in a friendly atmosphere because that's been my experience. People who want to come together in a friendly environment and get guidance on looking at how students learn, looking at the learning process and thinking about how they can use that information (on how students learn) to teach in their classrooms or laboratories. (1996 Participant)

If you choose to become involved in CCLE, you can expect to meet with a group of 7-8 faculty members for 1.5 hours every week over the academic year. You will have a CCLE staff facilitator to help keep your group focused and working together to examine in-depth the process of learning. Although you will be exposed to some teaching techniques and have opportunities to attend some specific workshops, the emphasis of this program is on learning.

I think that they can expect to get a richer view of teaching that they would not have otherwise been able to obtain on their own. You're benefiting from the experiences of your colleagues. People share things they've tried in class that have worked and things that haven't. It just enables you to learn far more about teaching than you could possibly do on your own. (1995 Participant) 
I would emphasize that [participation in CCLE is] an opportunity to develop your own thinking about learning and teaching, primarily by interacting with a group which is also interested in the same thing, and collaboratively come up with something useful to you... (1996 Participant)

We realize that 1.5 hours per week is a substantial time commitment. However, we feel that you will find it a rewarding and stimulating experience, and one that just might profoundly change your view of teaching.

CCLE groups for the 96-97 academic year begin working in early September. You need not be teaching currently to participate. If you have questions or comments, please email CCLE Director Katherine Sanders or Assistant Director Chris Carlson-Dakes, at ccle@macc.wisc.edu. To sign up, please fill out the back of this form and return it to us in campus mail by August 28. 